\title{
Implementing Electric Consent Aimed at People Living with Dementia and Their Caregivers: Did We Forget Those Who Forget?
}

\author{
Yvonne O' Connor \\ Business Information Systems, \\ UCC, Ireland \\ y.oconnor@ucc.ie
}

\author{
Ian Twohig \\ Business Information Systems, \\ UCC, Ireland \\ ian.twohig@ucc.ie
}

\author{
Leona O'Brien \\ Business Information Systems, \\ UCC, Ireland \\ leona.obrien@ucc.ie
}

\begin{abstract}
As policy flows down from law and/or regulation (e.g. GDPR) our individual privacy concerns give rise to demands on improving accessibility, awareness and comprehension, the topic of eConsent is becoming more prevalent. We provide a critical voice by considering, but also challenging, the underlying assumptions that the status quo of eConsent design and implementation is appropriate for all people in society. By answering "what eConsent characteristics are prevalent in the context of dementia applications?", this paper identifies that the "one size fits all" ethos for eConsent is not applicable in every context. As a result, a taxonomy that depicts the multifaceted concept of eConsent is proposed. It makes us aware of the different ethical, legal, social and technical implications of ICT use and provides an opportunity to create discourse in this area. It argues that future research examining the effectiveness of innovative ICTs must take the eConsent process into account.
\end{abstract}

\section{Introduction}

For decades, the Information Systems (IS) discipline has elevated the importance of information privacy in theory and practice $[1,2]$. Various theoretical perspectives have emerged in information privacy literature, ranging from research which provides a descriptive overview [3] to research which provides testable hypotheses and explanations [cf. 4]. The central argument posits that understanding and controlling how one's personal information is acquired and used is a complex and challenging undertaking that requires time, due diligence and often a legal background to ensure citizens' are aware of how their information is stored, accessed and/or processed [5-7].

Advances in information and communication technology (ICT), especially the use of assistive technologies in the homes of many people living with dementia and their informal caregivers have raised concerns about information privacy and its impacts [8, 9]. For personal information to be obtained, users of information and communication technology are required to provide their informed consent [10], more specifically their informed electronic consent (referred herein as eConsent) [6, 7, 11]. According to Beauchamp and Childress [12], valid informed consent must include three major elements: (1) disclosure of information, (2) competency of the patient (or surrogate) to make a decision, and (3) the voluntary nature of the decision. However, a recent empirical study [13] found that these elements may not be fully implemented in existing eConsent processes. While capturing written, verbal and implied consent from people living with dementia for research projects and/or medical treatment(s) is well documented [13], evidence of how developers should implement eConsent, vis-à-vis assistive technologies (mobile applications), is less clear [11]. Recent calls $[6,7,14,15]$ have proposed for more research to be conducted to fully understand the implications around eConsent via assistive technologies.

This paper investigates the eConsent process of mobile applications available to people living with dementia and their informal caregivers from a 'political-technological entwining' perspective. In doing so, this can (1) create awareness around political implications in technology design and the potential perils it might bring citizens (1) improve our understanding of how eConsent is currently designed to capture information privacy demands of end-users, and (2) help build a taxonomy that depicts the multifaceted concept of eConsent targeted at a vulnerable cohort in society. Empirical observations of the eConsent process through a systematic market review of mobile applications are used to describe the current problems related to implementing eConsent aimed at People living with Dementia and their caregivers. A systematic market review is 
considered an apt approach for capturing data as it provides the actual status quo of the eConsent design process implemented and used in society at the time of writing. Some researchers may argue that interviews with developers may provide richer insights into the eConsent design process than empirical observations through a systematic market review. We agree that qualitative research provides ample opportunities to (1) explore the deeper structure of ideas presented by interviewees and (2) understand phenomena "as it is lived, felt, undergone, made sense of and accomplished by human beings" [16 pg.84]. However, this paper reflects the first phase of research in this area. The authors intend to conduct qualitative research in the future. The aim of this paper is to critique our existing ways of designing eConsent, question the applicability of this process and make us ponder on whether or not we have forgotten about those individuals who forget?

The remainder of this paper is structured as follows: Assistive technologies are defined and classified according to existing research. The concept of eConsent is subsequently defined, whereby legislation and the associated characteristics of eConsent is outlined. Building from this, a detailed description of the systematic market analysis performed including exclusion and inclusion criteria as part of this study are provided. The findings are presented and discussed before concluding the paper with contributions for both theory and practice.

\section{Background}

At present, the global population is growing dramatically. Within the rapid rates of population growth, the fastest growing segment in the global population is over 60. The World Health Organisation (WHO) reports that one in every five people by 2050 will be 60 years or older, totalling two billion people worldwide [17]. In view of the rapid ageing of the population, dementia as a multi-faceted syndrome [18] is quickly becoming a major public health issue [19]. Many new Information and Communication Technologies (ICT) are being designed and developed to circumvent the potential lack of resources in the future [20], with assistive technologies becoming increasingly commonplace in residential environments for storing and processing personal data.

\subsection{Assistive Technologies}

There exists a number of definitions for assistive technologies in aged care [21], whereby the term is often used interchangeably with other terminology including, electronic assistive technology, telecare, cognitive prosthetics, technology-based reminding support, and pervasive computing [22]. Assistive technologies are defined by the World Health Organisation [23] as those whose "primary purpose is to maintain or improve an individual's functioning and independence to facilitate participation and to enhance overall well-being". Such technologies are often employed in various contexts such as day care facilities or care homes, but are predominantly used in residential environments [24, 25]. As a result, the definition for assistive technologies has been further extended to also incorporate the caregiver, who provides support and care to people living with dementia, proposing that assistive technologies reduces the burden on informal caregivers [c.f. 22, 26]. Informal caregivers are described as unpaid helpers (e.g. family, friends, and neighbours) who assist people living with dementia (and other disabilities) [27].

In view of these definitions and in the context of this study, it can be interpreted that assistive technologies are often designed for people living with dementia and/or their caregivers, to facilitate the operationalisation of at least one activity within a particular context. Assistive technologies can be classified as event-based or continuous-based transmission and analysis [28]. The authors define an event-based transmission and analysis system as "one that records the occurrence of particular, discrete events, throughout the designated care period" (p.367) whereas a continuous-based transmission and analysis refers to "devices that record information constantly while in use" ( $p$. 368). Building on the numerous systematic reviews focusing on assistive technologies aimed at people living with dementia and their caregivers [cf. 29, 30, 31], event-based transmission and analysis include mobile Phones (e.g. entering the date/time that medication was consumed) which require users to physically enters data sporadically based on an event occurring. Such technologies are focused on early to middle stage dementia. Continuous-based transmission and analysis assistive technologies include video surveillance (via mobile devices or camera installations), mobile devices using global positioning tracking whereby data is constantly captured without the 
physical input from user. Such technologies are focused on middle to late stage dementia.

It is argued that such ICT improve the quality of life for people living with dementia by extending community based living, enhancing independence and reducing the need for more constraining interventions and provide timely, efficient and effective care to the partially or totally dependent patient [32, 33]. Yet, Rosenberg and Nygård [34] and Thorstensen [14] argue that there remains a dearth of knowledge about the inevitable process that occurs when ICT is introduced into the homes of people living with dementia. Furthermore, from a review of existing literature, Mahoney et al. [35] found that frequently cited ethical concerns around home monitoring ICT for people living with dementia included clarification of informed consent (accounting for $50 \%$ of the concerns raised). Tassé and Kirby [36] further argue that there is limited standards or guidelines on how best to implement consent via technological devices (commonly referred to as eConsent). The next section defines consent and identifies current legislation which examines the concept.

\subsection{Consent: Definition, Characteristics and Legislation}

Consent is a multifaceted concept that has not received much attention in IS literature [37]. One of the central principles underpinning research on information privacy and the establishment of legislation and directives is to increase digital citizen awareness surrounding consent for data processing and usage [38]. For instance, The General Data Protection Regulation (GDPR) is a European Union regulation comprising eleven chapters, totalling 99 articles with 173 recitals. This regulation came into effect in May 2018 and mandates that data controllers and processors (i.e. in this context, the organisations who own assistive technologies) are required to emphasise transparency, security and accountability, while concurrently standardising and strengthening the right of European citizens to data privacy [38].

GDPR defines 'consent' of the data subject as the means by which "any freely given, specific, informed and unambiguous indication of the data subject's wishes by which he or she, by a statement or by a clear affirmative action, signifies agreement to the processing of personal data relating to him or her". The definition of eConsent, as it pertains to this study, embraces the definition provided by the GDPR but binds it within a digital environment.

Building on Beauchamp and Childress [12], valid informed eConsent must include the following: (1) Threshold Elements (Preconditions): Competence (to understand and decide) and Voluntariness (in deciding); (2) Information Elements: Disclosure (of material information); Recommendation (of a plan) and Understanding (of a. and b.); (3) Consent Elements: Decision (in favour of a plan) and Authorisation (of the chosen plan)

The basic requirements for the effectiveness of a valid legal consent are defined in Article 7 ("Conditions for Consent") and specified further in recital 32 of the GDPR. As policy cascades down from law and regulation [39], individuals providing their consent must now be aware of how their personal data will be processed. Articles 5 ("Principles relating to processing of personal data"), 6 ("Lawfulness of Processing"), 9 ("Processing of special categories of personal data"), 10 ("Processing of personal data relating to criminal convictions and offences") and 11 ("Processing which does not require identification") set out the principles in relation to how personal data is processed under GDPR. Recital 63 expands on the rights of the data subject with regard to the type of access they are entitled to in relation to personal data. As a result, there exists different types of consent and by definition, eConsent. EConsent can be explicitly or implicitly provided [adapted from 40]. Explicit eConsent requires that an individual "signifies" his or her agreement with a data controller by some active communication between the parties (e.g. Clicking a Check-box on a registration page) or implicit eConsent which arises where eConsent may reasonably be inferred from the action or inaction of the individual (e.g. Completing the registration process and submitting details or completing an online survey) [41]. Additionally, the eConsent process can facilitate a single (i.e. one option) or range of mechanisms (i.e. several options) for obtaining valid informed eConsent so that users are better positioned to manage what data is accessed, captured and processed [42].

\section{Political-Technological Entwining}

The idea of eConsent and the background of GDPR are highly political. This is perceived as political as it focuses on the use of technologies to solve societal problems [43, 44]. In his book, Susskind [45] provides a very recent argument 
pertaining to the interpenetration of politics and technology. He uses the insights of political philosophy to show how technological designs and future innovations influence how society perceive issues of power, liberty, democracy, and social justice. Similarly, Turner [46] speaks about 'machine politics' and how the rise of the internet is giving a parallel rise in a new age of authoritarianism. Yet, it is argued that political implications in design is an under-researched area [47]. In her work, Jasanoff [48] argues how technology is influencing society yet, this currently goes unchallenged by citizens. She further argues there is a need to dissect the way technological innovations consume power and consider how we might regain control. One approach in which society can maintain control in this technological era is through the eConsent process. This paper, therefore, seeks to answer the following research question: "What eConsent characteristics are prevalent in the context of dementia applications?"

\section{Method}

We conducted empirical observations from a systematic market review on mobile health applications available on the marketplace. Mobile health applications, more specifically Android applications, were selected from the broad range of assistive technologies for the following reasons:

- Android devices are found to be a popular brand amongst the elderly population [49]

- Easily accessible in the home place

- Access to both people living with dementia and caregiver

- Commercially/readily available to end-users

At the time of the market review, (June 2019 - present), 91 applications were commercially available to the public for download, based on the search keyword "Dementia". These applications were initially screened based on the year in which they were made available to the public. As GDPR has heightened the awareness and regulations pertaining to the process of consent, the applications were classified as 'Pre-GDPR' or 'Post-GDPR', if they were developed and deployed prior to or after GDPR became enforceable on the 25th May 2018, respectively. In total, 63 applications were categorised as 'PreGDPR', with the remaining 28 applications categorised as 'Post-GDPR'. Noteworthy, we also cross-examined any 'Pre-GDPR' applications for software updates since the introduction of GDPR.
As a result, 51 applications were included for further examination.

For this review, the inclusion criteria included 1) Applications which captured personal data; 2) available to the public post 25th May 2018; 3) targeted at people living with dementia and/or their caregivers; 4) Must be designed and developed using English language. Exclusion criteria included applications which were 1) static applications (i.e. present content to the user, with no data capture requirements; 2 ) made available to the public prior to 25th May 2018, with no subsequent software updates; 3) targeted at clinicians/researchers; 4) did not explicitly state their target audience; 4) Non-English.

The following is the breakdown of the 51 applications into the categories on the Android play store [50] - Books \& References $(\mathrm{n}=1)$; Casual $(\mathrm{n}=1)$; Education $(\mathrm{n}=4)$; Entertainment ( $\mathrm{n}$ $=3)$; Health \& Fitness $(n=18)$; Lifestyle $(n=2)$; Medical $(\mathrm{n}=14)$; Memory Tests $(\mathrm{n}=1)$; Music and Audio $(\mathrm{n}=1)$; Not categorised $(\mathrm{n}=2)$; Puzzle $(n=1)$ and Social $(n=3)$.

This research is primarily focused on applications which require the user to submit personal data (i.e. not static applications). The 51 applications were reviewed and assessed based on their description and sample screen shots to account for any static applications and the application's target audience. As a result, 38 applications were omitted based on the inclusion/exclusion criteria; leaving 13 applications in the categories of Health and Fitness, Medical and Social $(\mathrm{n}=5,5$ and 3 , respectively).

13 applications remained for the final assessment and inclusion in this study. Three researchers were involved in this study; One researcher has a legal background, a second researcher has experience of living with a person who had dementia and has an Information Systems background while the third researcher has an Information Systems background and experience evaluating mobile applications.

\section{Findings}

This section presents the findings from the study. Downloads of the applications range from 10 to 1000 , with 10 applications receiving feedback from users. Table 1 highlights the target audience of the mobile applications identified as part of this study. From the 13 applications analysed as part of this study, 3 applications can be employed by both the patient (i.e. A person living 
with dementia) and their caregiver. The remaining 10 applications are equally targeted at either the caregiver or the patient. The categories of 'Health and Fitness' and 'Medical' account for 5 applications each, with the remainder of the applications categorised as 'Social'. These categorisations, or tags as termed by the Google Play Store, describe the content and functionality of applications for users and can determine where an application is displayed on Google Play, and the peer groups that the application is compared against [50].

Table 1: Target Audience of Applications

\begin{tabular}{|c|c|c|c|c|}
\hline Category & 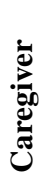 & 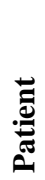 & 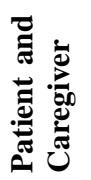 & స్ \\
\hline Health \& Fitness & 2 & 2 & 1 & 5 \\
\hline Medical & 2 & 1 & 2 & 5 \\
\hline Social & 1 & 2 & 0 & 3 \\
\hline Total & 5 & 5 & 3 & 13 \\
\hline
\end{tabular}

10 applications were categorised as "Eventbased", meaning that the user recorded a minimum of one discrete event at a particular point-in-time. Of the remaining 3 applications, one application (App043) continuously captured data, postinstallation of the application. Two outstanding applications, from the 13 applications included for analysis, had 'elements' of continuity in terms of capturing data. This means that certain features had to be activated within the application, by the user, to enable the continuous capture of data.

The findings reveal that the eConsent process was predominantly explicit in nature (often requiring users to tick a check-box prior to proceeding). These applications would first require users to read 'Terms and Conditions' and/or 'Privacy Policy' statements (often text heavy web application pages which redirect the user from the registration page) before proceeding with their eConsent by ticking the "I Agree" checkbox. Yet, no data was captured to reflect that the former activity (i.e. reading and interpreting 'Terms and Conditions' and/or 'Privacy Policy' statements) was performed. Additionally, the findings identify that users were provided with an 'All or Nothing' approach to using these mobile applications. If the user failed to agree with all the 'Terms and Conditions' and/or 'Privacy Policy' statements, then s/he was not permitted to use the application. Six of the applications were categorised as providing 'Implicit' consent and was based on providing personal details at the time of registration. No 'Terms and Conditions' and/or 'Privacy Policy' statements were provided at the time of registration. In this context, the user is not aware of how their data will be accessed, stored or processed after registration as no information is provided (See Table 2 for more information).

One application (App058) offered more than a single method of controlling how user data would be accessed, stored and/or processed by the owners/developers of the mobile application. This application was targeted to be used by both the caregiver and patient simultaneously, permitting the person living with dementia to opt-out (explicitly decide to have their profile deleted). The majority of the applications offered only a single method of control to its users. That means, it does not provide users with the means to select their preferences (of how their data is accessed, stored and/or processed) directly on the mobile applications.

Table 2: Analysis of eConsent Process

\begin{tabular}{|c|c|c|c|}
\hline AppId & $\begin{array}{l}\text { Type of Data } \\
\text { Capture }\end{array}$ & $\begin{array}{l}\text { Explicit / } \\
\text { Implicit }\end{array}$ & $\begin{array}{l}\text { Control } \\
\text { Mechanis } \\
\text { m }\end{array}$ \\
\hline $\begin{array}{l}\text { App } \\
003\end{array}$ & $\begin{array}{l}\text { Event-based, } \\
\text { with } \\
\text { continuous } \\
\text { data capture } \\
\text { features. }\end{array}$ & $\begin{array}{l}\text { Implicit-Based } \\
\text { on providing } \\
\text { registration } \\
\text { details. }\end{array}$ & $\begin{array}{l}\text { Single } \\
\text { option. }\end{array}$ \\
\hline $\begin{array}{l}\text { App } \\
006\end{array}$ & Event-based & $\begin{array}{l}\text { Explicit-select } \\
\text { a minimum of } \\
\text { one checkbox } \\
\text { (from } 2 \\
\text { available) }\end{array}$ & $\begin{array}{l}\text { Single } \\
\text { option. }\end{array}$ \\
\hline $\begin{array}{l}\text { App } \\
028\end{array}$ & Event-based & $\begin{array}{l}\text { Implicit-Based } \\
\text { on providing } \\
\text { registration } \\
\text { details. No } \\
\text { Terms and } \\
\text { Conditions/ } \\
\text { Privacy Policy } \\
\text { statements } \\
\text { provided at } \\
\text { registration. }\end{array}$ & $\begin{array}{l}\text { Single } \\
\text { option. }\end{array}$ \\
\hline $\begin{array}{l}\text { App } \\
034\end{array}$ & Event-based & $\begin{array}{l}\text { Implicit-Based } \\
\text { on providing } \\
\text { registration } \\
\text { details. No } \\
\text { Terms and } \\
\text { Conditions/ } \\
\text { Privacy Policy } \\
\text { statements } \\
\text { provided at } \\
\text { registration. }\end{array}$ & $\begin{array}{l}\text { Single } \\
\text { option. }\end{array}$ \\
\hline $\begin{array}{l}\text { App } \\
043\end{array}$ & $\begin{array}{l}\text { Continuous - } \\
\text { once opened }\end{array}$ & $\begin{array}{l}\text { Explicit- } \\
\text { checkbox to be } \\
\text { selected. }\end{array}$ & $\begin{array}{l}\text { Single } \\
\text { option. }\end{array}$ \\
\hline $\begin{array}{l}\text { App } \\
054\end{array}$ & Event-based & $\begin{array}{l}\text { Explicit- } \\
\text { Toggle switch } \\
\text { to be selected to } \\
\text { indicate that }\end{array}$ & $\begin{array}{l}\text { Single } \\
\text { option. } \\
\text { Email } \\
\text { needs to }\end{array}$ \\
\hline
\end{tabular}




\begin{tabular}{|l|l|l|l|}
\hline & & $\begin{array}{l}\text { Terms and } \\
\text { Conditions/Priv } \\
\text { acy Policy } \\
\text { statements have } \\
\text { been read }\end{array}$ & $\begin{array}{l}\text { be sent by } \\
\text { user in } \\
\text { order to } \\
\text { explicitly } \\
\text { identify } \\
\text { what data } \\
\text { can be } \\
\text { captured } \\
\text { and } \\
\text { analysed. }\end{array}$ \\
\hline $\begin{array}{l}\text { App } \\
057\end{array}$ & Event-based & $\begin{array}{l}\text { Explicit- } \\
\text { checkbox to be } \\
\text { selected. }\end{array}$ & $\begin{array}{l}\text { Single } \\
\text { option. }\end{array}$ \\
\hline
\end{tabular}

\section{Discussion}

This study explores the current problems of implementing electronic consent aimed at people living with dementia and their caregivers. After a systematic market analysis, 13 Android-based mobile applications are analysed, focusing on the eConsent process. Consent to the capture of personal data, whether event-based or continuous, must be informed and based on an explicit affirmative action; clicking an 'I Agree' checkbox. The findings reveal that the majority of mobile applications aimed at caregivers and/or people living with dementia require explicit consent.

The findings further reveal that users are not provided with the means to identify and select their preferences directly on mobile applications. The option of providing users with a multiple range of mechanisms for them to monitor and consent for how their data is to be accessed, stored and processed is not a requirement for mobile application developers providing that they provide a clear, unambiguous option for obtaining informed consent, provide a means for the withdrawal of consent and guarantee that no data is captured prior to eConsent being obtained [51]. This would reflect that the threshold elements and information elements associated with [electronic] consent (as per Beauchamp and Childress [12]) would first need to be conspicuously provided to users. Based on this, the user would decide in favour of the process and provide their authorisation to proceed.

The preconditions to providing eConsent require that the user has the competency to understand and decide before volunteering in making the decision [12] and, in the case of people living with dementia, the capacity to make a particular decision [52]. Generally, capacity assessments for people living with dementia are rigorously performed by healthcare professionals [52]. The law assumes that people living with dementia have the capacity to make a particular decision at a specific time or in a specific situation unless there is contrary evidence [53]. To further add to this complex conundrum, capacity is context and decision-specific: a person living with dementia may retain the capacity for certain decisions, even if the capacity for other types of decisions is lost [54]. No application (targeted specifically at patients, analysed as part of this study) examined the capacity and/or competency of the user, who would be considered to be a vulnerable cohort in society. Going forward, mobile application developers should digitise commonly used assessments tools (e.g. The MacArthur Competence Assessment Tool for Clinical Research (MacCAT-CR), [55]) for determining capacity for informed consent to identify whether (or not) the user has the capacity to make an informed decision. While this could be a feature embedded within event-based AT, it would be more difficult to implement this as part of continuous-based AT.

In order to obtain informed eConsent requires the disclosure of information, recommendation of a plan and to understand this material [12]. A person living with dementia must therefore demonstrate that $\mathrm{s} / \mathrm{he}$ understands the information presented, appreciates how this information relates to their personal situation and rationally uses this information to arrive at a decision [54]. The ability to understand user agreements ('Terms and Conditions' and 'Privacy Policy' statements) and their ongoing changes is a challenge for people living with dementia. These text heavy agreements are very complex, full of jargon and require a lot of time to read and interpret by end-users [56]. Unfortunately, people living with dementia suffer from progressive cognitive disabilities and can have difficulties concentrating on and interpreting long pieces of written text [32]. The accessibility of existing 'Terms and Conditions' and 'Privacy Policy' statements must be reconsidered by mobile application developers. Universal Design Guidelines [57] must be embraced to make sure the content of user agreements is presented in a way that the user can interact with. When designing user agreements, mobile application developers should embrace the plethora of multi-media options available to them (e.g. audio, animation, video, voice) to minimise the complexity associated with existing approaches. Additionally, research [5] has shown that users of technology embrace a 'just-tick agree' approach when providing their eConsent without fully understanding what they are consenting to. 
As technology evolves, both the disclosure and the recommendation phases, proposed by Beauchamp and Childress, might be operationalised by machines [14]. Articles 13, 14 and 15 , in Section 2 of GDPR specifically refers to meaningful information being provided on the logic involved in automated decision-making "as well as the significance and the envisaged consequences of such processing for the data subject." Where profiling is defined as “...any form of automated processing of personal data consisting of the use of personal data to evaluate certain personal aspects relating to a natural person, in particular to analyse or predict aspects concerning that natural person's performance at work, economic situation, health, personal preferences, interests, reliability, behaviour, location or movements;"'. A person living with dementia must also demonstrate that they have the ability to maintain a consistent choice over time. There exist different stages of dementia (Early, Middle and Late) and as the person living with dementia progresses along these stages, their capacity to make decisions diminished [58]. As people living with dementia suffer from declining decision-making capacity and potential advancing memory loss [32], the introduction of reflective quizzes could ensure that the person living with dementia is maintaining a consistent choice over time. This can help identify when a caregiver is required to step-in and assist with decision making.

Going forward, mobile application developers should implement an eConsent process which moves beyond a once off static agreement but instead to a dynamic, ongoing-layered, tailored approach for people living with dementia which also incorporate their caregivers. However, aligning with the work of Pethig \& Kroenung [59] the intention is that such specialized information systems should not further activate an already stigmatized cohort in society. The dynamic approach, however, should allow people living with dementia and/or their caregiver to modify their settings to opt-in or opt-out of certain components as opposed to the current 'all or nothing' approach. Expecting a standard response from all individuals who use assistive technologies is neither feasible nor realistic. Furthermore, it should be designed and developed with people living with dementia and their caregivers. Information Systems research has long argued that the end-user is a key stakeholder in designing usable technologies [60]. People living with dementia and their caregivers, unfortunately, are often excluded from research (including the design of assistive technologies) but more concentrated efforts are being made to include people living with dementia in design activities [61].

The implementation of informed eConsent varies across stages of dementia as well as the particular technology at hand. Event-based assistive technologies are predominantly used at an early-stage of dementia whereby the person living with dementia provides their own eConsent. As the disease progresses, the assistive technology of choice is less obtrusive to the person living with dementia and captures their data on a continuous basis transmission and analysis [28]. Consent is often provided by caregivers, especially at latter stages of the disease's progression. However, the use of continuous-based AT is generating extensive ethical debates surrounding the balance of the person's safety weighed against their residential autonomy [62]. The issue of providing eConsent is further complicated due to the different types that can be employed, but also the proxy-decision making.

If the initial eConsent is explicit and provided by the person at early-stage dementia for any assistive technology, then those initial preferences remain valid. This is of particular importance for when the caregiver is unsure of how best to deliver the expressed wishes of the person living with dementia with respect to continuous-based AT.

At middle or late-stage dementia, eConsent can be provided by the proxy (i.e. caregiver) for any assistive technology. The caregiver should be in a position to view and modify how the data belonging to the person living with dementia is accessed, stored and processed. This scenario would also be valid in situations whereby the initial eConsent was implicit in nature and the person living with dementia cannot maintain a consistent choice over time.

One means of supporting decision-making around the use of assistive technologies in residential environments, and the capture of personal data, is for people living with dementia to specify their preferences in advance [63]. Nonetheless, there is also a need to recognise the competing interest of privacy within this context. Article 22, The United Nations Convention on the Rights of Persons with Disabilities [64], recognises the right to privacy stating "No person with disabilities...shall be subjected to arbitrary or unlawful interference with his or her privacy, family, home or correspondence or other types of communication or to unlawful attacks on his or her honour and reputation. Persons with disabilities have the right to the protection of the law against 
such interference or attacks." Additionally, GDPR, Article 25, on "Data protection by design and by default" refers to the necessary safeguards to be considered and implemented to protect the rights of the data subject. Yet, it is not known when and how assistive technologies (especially continuous-based transmission and analysis) will cease to be helpful and start to infringe on the rights and freedom of people living with dementia. While there is a clear obligation on State Parties to research and develop new technologies to ensure the equal rights of those with dementia, there is also a clear conflict on the ability of people living with dementia and their caregivers to consent to the use of assistive technologies and how far that consent goes.

\section{Conclusion}

The number of people living with dementia is expected to grow greatly in future years [65]. Assistive technologies can improve the lives of people living with dementia and their caregivers with legislative articles going some way to ensuring their rights are upheld. Future research testing the effectiveness of innovative assistive technologies for people living with dementia and their caregivers must take the informed eConsent process into account.

From the onset of this paper, we set out to critique the existing design approach of eConsent aimed at a vulnerable group in our society, question the applicability of this process and make us ponder on whether we have forgotten, or not, about those individuals who forget? Unfortunately, the results reveal that we may have indeed neglected to consider People Living with Dementia and their caregivers.

This paper contributes to theory by exploring the political-technological entwining pertaining to eConsent. The findings presented here are also not unique to people living with dementia; instead, the results could be true for everyone. If we continue to embrace this 'Just click agree' mentality we are guilty of assuming that technology is "an apolitical and amoral force... warp[ing] the meaning of democracy and citizenship" [48]. We need to explore the political implications in technology design and the potential perils it might bring citizens. Researchers need to examine the sociotechnical-political dimensions of new innovations

While recent on-going efforts are focusing on improving the electronic consent process [cf. 5, 7, $11,66]$, there is still room for improvement. We challenge the assumption that the "one size fits all" ethos is applicable for designing and implementing eConsent. Organizations have found many diverse ways in which personal data can be extracted and used through information and communication technologies. Yet, they remain stagnant on the design and development of eConsent processes; acquiring, storing and processing as much data as possible. Is the eConsent design forever trapped in this current, stagnant design methodology; Do organizations not want to simplify the eConsent process as it may potentially impact their bottomline or are recent policy changes now beginning to shift our attention to this area of research? Going forward, researchers should consider how we can address this issue from as design science research perspective.

For this paper, we explored the eConsent process focusing on one affected target group. We focused on People Living with Dementia due to their diminishing cognitive abilities and how, over time, this can have an impact on their competence, voluntariness and decision-making which are core components to providing eConsent. The diminishing cognition and proxy decision-maker makes this group unique in society when it comes to engaging with the eConsent and their data privacy rights as individuals. However, the researchers acknowledge that the issue pertaining to eConsent does not only occur in the field of work with seniors and chronically ill people. There is a fundamental problem regarding eConsent in general. We therefore call for further research to be examined in this domain.

Acknowledgement: Funded by College of Business and Law Research Strategic Fund Report, University College Cork, Ireland.

\section{References}

[1] Straub Jr, D.W. and R.W. Collins, Key information liability issues facing managers: Software piracy, proprietary databases, and individual rights to privacy. Mis Quarterly, 1990: p. 143-156.

[2] Dinev, T., et al., Information privacy and correlates: an empirical attempt to bridge and distinguish privacy-related concepts. European Journal of Information Systems, 2013. 22(3): p. 295-316.

[3] Culnan, M.J., Policy to Avoid a Privacy Disaster. Journal of the Association for Information Systems, 2019. 20(6): p. 1.

[4] Yaraghi, N., R.D. Gopal, and R. Ramesh, Doctors' orders or patients' preferences? Examining the role of physicians in patients' privacy decisions on health information exchange platforms. Journal of the Association for Information Systems, 2019. 20(7): p. 14. 
[5] O'Connor, Y., et al., Privacy by Design: Informed Consent and Internet of Things for Smart Health. Procedia Computer Science, 2017. 113: p. 653658.

[6] Lindegren, D., et al., An evaluation of three designs to engage users when providing their consent on smartphones. Behaviour \& Information Technology, 2019: p. 1-17.

[7] Assale, M., E. Barbero, and F. Cabitza. Digitizing the Informed Consent: the challenges to design for practices. in 2019 IEEE 32nd International Symposium on Computer-Based Medical Systems (CBMS). 2019. IEEE.

[8] McRae, L., et al., Privacy and the Ethics of Disability Research: Changing Perceptions of Privacy and Smartphone Use. Second International Handbook of Internet Research, 2020: p. 413-429.

[9] Ienca, M. and E.F. Villaronga, Privacy and security issues in assistive technologies for dementia, in Intelligent Assistive Technologies for Dementia: Clinical, Ethical, Social, and Regulatory Implications. 2019. p. 221.

[10] Goldstein, M.M., Health information technology and the idea of informed consent. The Journal of Law, Medicine \& Ethics, 2010. 38(1): p. 27-35.

[11] Iwaya, L.H., et al. E-Consent for Data Privacy: Consent Management for Mobile Health Technologies in Public Health Surveys and Disease Surveillance. in MEDINFO 2019, the 17th World Congress on Medical and Health Informatics, Lyon, France, 25-30 August 2019. 2019. IOS Press.

[12] Beauchamp, T.L. and J.F. Childress, Principles of biomedical ethics. 2001: Oxford University Press, USA.

[13] Zazaza, L., H.S. Venter, and G. Sibiya. The current state of electronic consent systems in eHealth for privacy preservation. in International Information Security Conference. 2018. Springer.

[14] Thorstensen, E. Privacy and future consent in smart homes as assisted living technologies. in International Conference on Human Aspects of IT for the Aged Population. 2018. Springer.

[15] Novitzky, P., et al., Issues of Informed Consent from Persons with Dementia When Employing Assistive Technologies. Intelligent Assistive Technologies for Dementia: Clinical, Ethical, Social, and Regulatory Implications, 2019: p. 166.

[16] Schwandt, T.A., Qualitative inquiry: A dictionary of terms (2nd Ed). 2001, Thousand Oaks, CA: Sage Publications, Inc.

[17] World Health Organisation, W., Global strategy and action plan on ageing and health, A. http://www.who.int/ageing/WHO-GSAP2017.pdf?ua=1, Editor. 2017.

[18] Goldberg, L.R., et al., The critical importance of adopting a 'personhood lens' in reframing support and care for those with dementia. Dementia as Social Experience: Valuing Life and Care, 2018.
[19] Midtbust, M.H., et al., Perceived barriers and facilitators in providing palliative care for people with severe dementia: the healthcare professionals' experiences. BMC health services research, 2018. 18(1): p. 709.

[20] Singh, R., et al., Dynamic capabilities in home health: IT-enabled transformation of post-acute care. Journal of the Association for Information Systems, 2011. 12(2): p. 2.

[21] Vichitvanichphong, S., et al. Adoption of assistive technologies for aged care: A realist review of recent studies. in 2014 47th Hawaii International Conference on System Sciences. 2014. IEEE.

[22] Van der Roest, H.G., et al., Assistive technology for memory support in dementia. Cochrane Database of Systematic Reviews, 2017(6).

[23] World Health Organisation, W., URL: https://www.who.int/disabilities/technology/en/. 2019.

[24] Evans, J., et al. A systematic review of dementia focused assistive technology. in International conference on human-computer interaction. 2015. Springer.

[25] Ienca, M., et al., Intelligent assistive technology for Alzheimer's disease and other dementias: a systematic review. Journal of Alzheimer's Disease, 2017. 56(4): p. 1301-1340.

[26] Mortenson, W.B., et al., Development and preliminary evaluation of the caregiver assistive technology outcome measure. Journal of rehabilitation medicine, 2015. 47(5): p. 412-418.

[27] Vaingankar, J.A., et al., Care participation and burden among informal caregivers of older adults with care needs and associations with dementia. International psychogeriatrics, 2016. 28(2): p. 221-231.

[28] Cavoukian, A., et al., Remote home health care technologies: How to ensure privacy? Build it in: Privacy by design. Identity in the Information Society, 2010. 3(2): p. 363-378.

[29] Sriram, V., C. Jenkinson, and M. Peters, Informal carers' experience of assistive technology use in dementia care at home: a systematic review. BMC geriatrics, 2019. 19(1): p. 160.

[30] Suijkerbuijk, S., et al., Active involvement of people with dementia: a systematic review of studies developing supportive technologies. Journal of Alzheimer's Disease, 2019(Preprint): p. $1-25$.

[31] Ienca, M., et al., Intelligent assistive technology for Alzheimer's disease and other dementias: a systematic review. Journal of Alzheimer's Disease, 2017. 56(4): p. 1301-1340.

[32] Batchelor, R., et al., Challenges of ethical and legal responsibilities when technologies' uses and users change: social networking sites, decisionmaking capacity and dementia. Ethics and Information Technology, 2012. 14(2): p. 99-108.

[33] Schikhof, Y., I. Mulder, and S. Choenni, Who will watch (over) me? Humane monitoring in 
dementia care. International Journal of HumanComputer Studies, 2010. 68(6): p. 410-422.

[34] Rosenberg, L. and L. Nygård, Persons with dementia become users of assistive technology: a study of the process. Dementia, 2012. 11(2): p. $135-154$

[35] Mahoney, D.F., et al., In-home monitoring of persons with dementia: Ethical guidelines for technology research and development. Alzheimer's \& Dementia, 2007. 3(3): p. 217-226.

[36] Tassé, A.M. and E. Kirby, Is written informed consent outdated? The European Journal of Public Health, 2017. 27(2): p. 195-196.

[37] Bonnici, C.J. and L. Coles-Kemp. Principled electronic consent management: A preliminary research framework. in 2010 International Conference on Emerging Security Technologies. 2010. IEEE.

[38] EU General Data Protection Regulation. https://www.eugdpr.org/. 2018.

[39] Winter, S.J. and C. Saunders, The Personal in the Policy Cascade. Journal of the Association for Information Systems, 2019. 20(11): p. 1.

[40] Asim, M., et al., eConsent management and enforcement in personal telehealth, in ISSE 2012 Securing Electronic Business Processes. 2012, Springer. p. 209-216.

[41] Kliemt, H., The calculus of consent after thirty years. Public Choice, 1994. 79(3-4): p. 341-353.

[42] Friedman, B., E. Felten, and L.I. Millett, Informed consent online: A conceptual model and design principles. University of Washington Computer Science \& Engineering Technical Report 00-12-2, 2000. 8.

[43] Schot, J., The contested rise of a modernist technology politics. Modernity and technology, 2003: p. 257-278.

[44] Selwyn, N., Reconsidering political and popular understandings of the digital divide. New media \& society, 2004. 6(3): p. 341-362.

[45] Susskind, J., Future politics: Living together in a world transformed by tech. 2018: Oxford University Press.

[46] Turner, F., The rise of the internet and a new age of authoritarianism. Harper's Magazine, 2019.

[47] Carolan, M.S., Ontological politics: Mapping a complex environmental problem. Environmental Values, 2004: p. 497-522.

[48] Jasanoff, S., The ethics of invention: technology and the human future. 2016: WW Norton \& Company.

[49] Marakkalage, S.H., et al., Understanding the lifestyle of older population: Mobile crowdsensing approach. IEEE Transactions on Computational Social Systems, 2018. 6(1): p. 82-95.

[50] Android-Developer, W. 2019.

[51] Data Protection Working Party, A., Guidelines on consent under Regulation 2016/679. GDPR, 2018.

[52] Epley, N., A. Waytz, and J.T. Cacioppo, On seeing human: a three-factor theory of anthropomorphism. Psychological review, 2007. 114(4): p. 864

[53] Hegde, S. and R. Ellajosyula, Capacity issues and decision-making in dementia. Annals of Indian Academy of Neurology, 2016. 19(Suppl 1): p. S34.

[54] Darby, R.R. and B.C. Dickerson, Dementia, Decision Making, and Capacity. Harvard review of psychiatry, 2017. 25(6): p. 270-278.

[55] Palmer, B.W., et al., Determinants of capacity to consent to research on Alzheimer's disease. Clinical gerontologist, 2017. 40(1): p. 24-34.

[56] Plaut, V.C. and R.P. Bartlett III, Blind consent? A social psychological investigation of nonreadership of click-through agreements. Law and human behavior, 2012. 36(4): p. 293.

[57] Ruzic, L., et al. Development of universal design mobile interface guidelines (udmig) for aging population. in International Conference on Universal Access in Human-Computer Interaction. 2016. Springer.

[58] Werner, P., I. Stein-Shvachman, and A.D. Korczyn, Early onset dementia: clinical and social aspects. International psychogeriatrics, 2009. 21(4): p. 631-636.

[59] Pethig, F. and J. Kroenung, Specialized information systems for the digitally disadvantaged. Journal of the Association for Information Systems, 2019. 20(10): p. 5.

[60] Markus, M.L. and M. Keil, If we build it, they will come: Designing information systems that people want to use. MIT Sloan Management Review, 1994. 35(4): p. 11.

[61] Astell, A., et al., Involving older people with dementia and their carers in designing computer based support systems: some methodological considerations. Universal Access in the Information Society, 2009. 8(1): p. 49.

[62] Hall, A., et al., Moving beyond 'safety'versus 'autonomy': a qualitative exploration of the ethics of using monitoring technologies in long-term dementia care. BMC geriatrics, 2019. 19(1): p. 145.

[63] Thorogood, A., et al., Consent recommendations for research and international data sharing involving persons with dementia. Alzheimer's \& Dementia, 2018. 14(10): p. 1334-1343.

[64] A/RES/61/106., R., Convention on the Rights of Persons with Disabilities. United Nations, New York, 13 December 2006. 2006.

[65] World Health Organisation, W., Dementia: A Public Health Priority, A.a. http://apps.who.int/iris/bitstream/handle/10665/7 5263/9789241564458 eng.pdf;jsessionid $=\mathrm{A} 8418$ D99E4B1EF2FD72730E7E47DCF54? sequence= 1, Editor. 2012.

[66] Feldman, J., et al. Patient Perspective of electronic consent (eConsent) tool: A Proof of Concept Study. in APHA's 2019 Annual Meeting and Expo (Nov. 2-Nov. 6). 2019. American Public Health Association. 